\title{
CATÁLOGOS ESTRELA: CAPAS DOS ANOS 1940 E 1950
}

Wilma Ruth Temin, doutoranda

Universidade de São Paulo

wilma@areadg.com

Roberto Temin

Resumo: No âmbito da pesquisa sobre a criação e trajetória da marca da Manufatura de Brinquedos Estrela, indústria criada em 1937 e ativa ainda hoje, este artigo tem como foco a análise gráfica das capas dos catálogos de produtos produzidos pela empresa nos anos 1940 e 1950. Esses catálogos registravam todos os brinquedos produzidos e tinham miolo de no mínimo 50 páginas e capa colorida. Eles são fonte de pesquisa da história do design gráfico na medida em que contêm elementos como fotografias, ilustrações, marcas, textos explicativos e, principalmente, foram editados anualmente por mais de 50 anos, sem interrupção. Este trabalho procura registrar, divulgar e evidenciar o trabalho cuidadoso na execução desses impressos efêmeros.

Palavras-chave: Memória gráfica, design gráfico, Manufatura de Brinquedos Estrela

\begin{abstract}
In the context of research on the history of the brand of Manufatura de Brinquedos Estrela, industry created in 1937 and still active today, this article focuses on the graphical analysis of the covers of product catalogs produced by the company in 1940 and 1950. These catalogs, printed annually recorded all produced toys and had at least 50 pages and colorful cover. The research seeks to register, publicize and highlight the careful work in printing these ephemeral works.
\end{abstract}

Keywords: Graphic memory, graphic design, Manufatura de Brinquedos Estrela 


\section{INTRODUÇÃO}

Na primeira metade do século XX surgiram as primeiras fábricas de brinquedos do Brasil como a Atlântico, Adrianini, Metalma, Bonzo, Barlan e Estrela (FAYAD, 2010, p.122), na sua maioria, a partir de ideias empreendedoras de imigrantes europeus. (FAYAD, 2010, p. 122)

A Estrela nasceu em 1937, quando Siegfried Adler comprou uma pequena fábrica de bonecas de pano que estava à beira da falência e cujo nome era Manufactura de Brinquedos Estrela. Logo, a fábrica se expandiu e nos anos 1970 era a maior indústria de brinquedos do País e está ainda hoje em atividade.

Desde o início, a Estrela teve o cuidado de editar um detalhado catálogo de produto de pelo menos 50 páginas com fotos dos brinquedos, texto explicativos e capa colorida. Produção que se estendeu anualmente até 1997.

A proposta desse artigo é divulgar parte dos resultados obtidos na pesquisa sobre a trajetória gráfica da marca Estrela no contexto da história do design gráfico dos anos 1950, no Brasil. O estudo dos catálogos de produtos da empresa impressos nos anos 1940 e 1950 foi parte essencial da pesquisa.

No âmbito do estudo dos primeiros catálogos impressos pela Estrela optou-se pela análise gráfica das capas desses catálogos. A análise gráfica foi baseada nas categorias propostas por André Villlas-Boas em seu artigo Sobre análise gráfica, ou algumas estratégias para a difusão de um design crítico.

As capas, muitas delas assinadas por OK ou Kratzer (provavelmente O. Kratzer, artista desconhecido), podem ser, quando organizadas e analisadas, reveladoras obras gráficas a serviço da indústria. Esse conjunto de impressos efêmeros reflete, a seu modo, a linguagem gráfica da época.

\section{BRINQUEDOS ESTRELA}

A Estrela nasceu em 1937, em São Paulo, quando o imigrante Siegfried Adler, que ainda em Berlim criava desenhos para estamparias, comprou uma pequena fábrica de bonecas de pano por 11 contos de reis. A fábrica tinha cerca de 20 funcionários incluindo a modelista, as costureiras, os rapazes que faziam os moldes e o contador, além do antigo dono da fábrica (MEFANO, 2005, p. 88). As bonecas, confeccionadas em tecido de algodão barato eram vendidas nos mercados populares. Poucos meses depois a fábrica começou a produzir, também, carrinhos de madeira e outros brinquedos.

Posteriormente, com o aperfeiçoamento da fabricação de bonecas, iniciou-se a confecção das cabeças utilizando a chamada composição, que consistia na mistura de serragem e goma arábica prensada. Ao secar, a cabeça era pintada na cor da pele e eram acrescentados os olhos, o nariz e a boca. Essas novas bonecas tinham a aparência dos produtos importados, o que fez ampliar o perfil econômico dos clientes e lojas compradoras. (MEFANO, 2005, p.88-89)

Durante a Segunda Guerra Mundial, com a restrição às importações de manufaturados, a Estrela e as indústrias de brinquedos nacionais tiveram um crescimento acelerado. Já em 1939, a Estrela, começou a produzir bonecas que tinham olhos de dormir, cabeça e pés flexíveis e articulados, e que falavam "mamãe" (Figuras 1 e 2). Elas vestiam roupas especialmente desenhadas e muitas tinham o rosto lavável. Algumas eram vendidas em caixas luxuosas como a boneca Shirley Temple e a Clara 
que tinha mais de meio metro de altura, na época, a maior do Brasil. Em 1943, a fábrica começou a produzir os brinquedos com personagens licenciados da Disney mesma época que fazia sucesso um conjunto completo de caubói para meninos. Quatro anos depois a Estrela começou a fabricar um brinquedo à pilha, de perguntas e respostas, que acendia luzes quando a resposta dada pelo jogador estava correta. (Figura 3). (ARRABAL, s/d, p.35-36)

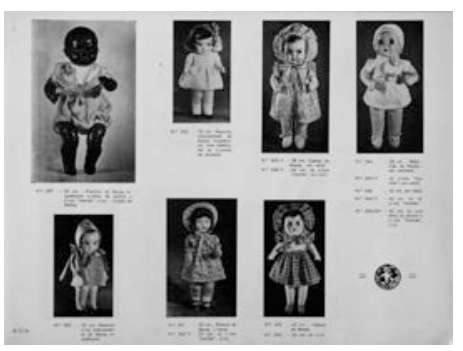

Figura 1

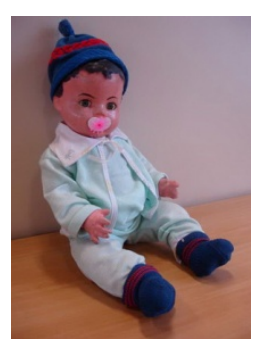

Figura 2

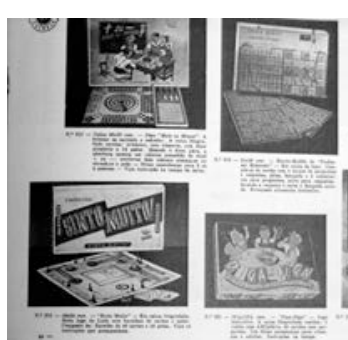

Figura 3

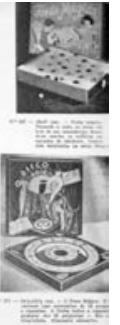

Figura 4

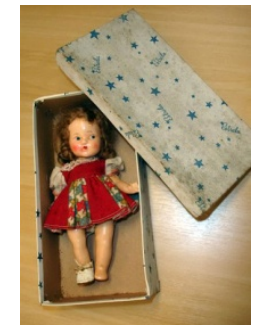

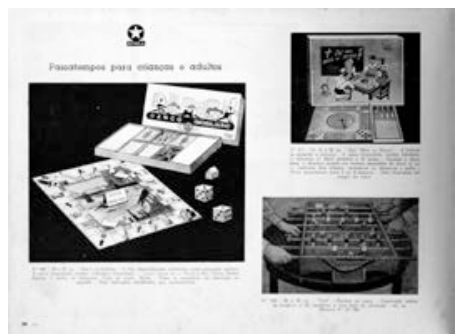

Figura 5

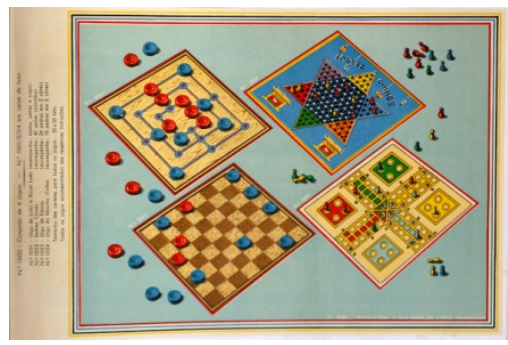

Figura 6

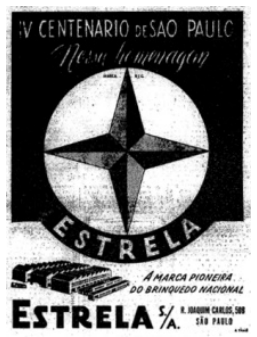

Figura 7

(Figura 1 - página do catálogo Estrela de 1942 mostrando boneca com olhos de dormir, figura 2 boneca Estrela de 1947 que fala "mamãe", figura 3 - página do catálogo Estrela de 1947 que mostra o jogo Professor Eletronic, figura 4 - boneca Estrela de 1946 na embalagem original, figura 5 - página do catálogo Estrela de 1945, figura 6 - página colorida do catálogo Estrela de 1943 com jogos de tabuleiro e figura 7 - anúncio publicado no jornal $O$ Estado de S. Paulo em 9 de julho de 1954 com a marca Estrela) ${ }^{1}$

Em 1944, a Estrela abriu seu capital sendo uma das primeiras empresas do Brasil a tornar-se sociedade anônima. Tinha, na época, representantes de vendas em 15 cidades brasileiras, um escritório para compras em Nova lorque e era distribuidora exclusiva de brinquedos de borracha, trens elétricos e patins de fábricas americanas e inglesas.

Após a Segunda Guerra Mundial o plástico chegou à manufatura de brinquedos e começou a era das bonecas de poliestireno o que tornou o uso de máquinas industriais essencial. Em depoimento, Mario Arthur Adler, filho do fundador, comenta: "Primeiro, a Estrela mandou fazer os moldes plásticos em outra firma, enquanto não tinha máquina; depois (...) passou a fabricar tudo. Os brinquedos de plástico eram muito mais baratos (...) e muito mais leves também. Seus recursos eram muito maiores, e a criança podia brincar de vestir e despir a boneca; por exemplo, com uma boneca de serragem, se forçava um pouco, ela quebrava." (MEFANO, 2005, p.91).

\footnotetext{
${ }^{1}$ Os catálogos da Estrela reproduzidos neste artigo fazem parte do acervo pessoal de Vivian Adler Zolko e foram fotografados por Roberto Temin. As bonecas pertencem à coleção do Museu Histórico Nacional e a foto da figura 4 é de Denize Pereira. O anúncio pertence ao acervo do jornal O Estado de S. Paulo.
} 
Os soldadinhos de chumbo foram substituídos por bonecos de plástico e iniciou-se a fabricação de brinquedos infláveis. Em 1948, a Estrela lançou bonecas que sentavam e andavam através de um mecanismo especialmente projetado. (ARRABAL, $s / d, p .61)$.

Siegfried, o fundador da empresa, faleceu no final dos anos 1950 deixando uma empresa com escritórios de representação em diversos países das Américas, na Europa e em todo o Brasil, com capital aberto e dividido em ações bem cotadas na Bolsa de Valores de São Paulo. Seu filho Mario promove, então, a modernização da companhia, implantando de forma profissional o marketing e enfatizando a divulgação através das feiras internacionais e programas de TV, chegando a ser o décimo quarto anunciante do País no final dos anos 1970 (ARRABAL, s/d, p.61). Em 1987, a Estrela tinha 50\% do mercado de brinquedos do Brasil, comercializava mais de 600 produtos e exportava para 42 países (O ESTADO, 1987, p.51). Em 1996 foi vendida para Carlos Alberto Tilkian e sob essa nova direção, construiu-se duas novas unidades fabris. Mas com um prejuízo de 23,8 milhões em 2015, a empresa fez uma Oferta Pública de Aquisição de Ações para poder fechar seu capital na BM\&F Bovespa. (O ESTADO, 2015, p. b11)

\section{OS CATÁLOGOS IMPRESSOS DA ESTRELA}

Os padrões de qualidade das manufaturas europeias e norte-americanas, desde o início, foram modelos para as fábricas de brinquedos brasileiras que também faziam acordos de representação e licenciamento de marcas e de personagens estrangeiros que traziam um padrão internacional ao produto nacional, às suas embalagens (Figura 4) e impressos. Inseridos nessa busca de qualidade os catálogos dos produtos Estrela foram produzidos anualmente desde sua fundação, em 1937. Em entrevista, Mario (ADLER, 2015) conta que os dois primeiros catálogos constituíam-se de fotografias coladas em papel cartão, como um álbum de fotos. Ele relata que a execução dos catálogos impressos, que no início tinham mais que 25 folhas impressas a uma ou duas cores, e com até quatro páginas coloridas encartadas (Figura 6), sempre foi custosa para a empresa e que, desde o início, havia um cuidado especial da diretoria com essas publicações.

Com representantes e compradores em todo País os catálogos serviam como referência pois mostravam as fotografias dos produtos produzidos e a descrição de suas caraterísticas principais como medidas, material de fabricação e tipo de embalagem (Figura 5). E também o nome do produto e número de referência, detalhes importantes para quem tinha que revender mais de 500 tipos de brinquedos diferentes, às vezes só com pequenas variações entre os vários modelos.

Os produtos eram organizados por categorias, nas primeiras páginas das publicações apareciam as bonecas, depois brinquedos de madeira, metal, bolas e jogos. Na página inicial constava, sempre, telefones e endereços para contato. Os lojistas recebiam os catálogos no primeiro semestre do ano e eles tinham validade para dois anos e vinham acompanhados por uma lista de preços. Dos lojistas, eram esperados os pedidos de compra pelo correio.

\subsection{Análise gráfica}

A partir da sistematização proposta por André Villas-Boas foi feita a análise gráfica das capas dos impressos da Estrela. Ele propõe a análise da peça gráfica a partir de dois tipos de elementos: elementos técnico-formais (princípios projetuais como 
harmonia, unidade, síntese, balanceamento movimento e hierarquia; e dispositivos de composição como mancha gráfica, estrutura, centramento e eixo) e elementos estético-formais (componentes textuais como, títulos, subtítulos massas de texto legendas; componentes não textuais como fotografias, grafismos e ilustrações; e elementos mistos como gráficos e tabelas). (VILLAS-BOAS, 2009, p.10)

A escolha pelas capas estudadas deu-se porque são exemplos dos primeiros impressos da empresa e têm características gráficas comuns como serem compostas por dois elementos estético-formais: um título e uma ilustração; têm formato horizontal, diferentemente das que foram editadas a parir de 1955, com medidas que variam de $31 \mathrm{~cm}$ a $32 \mathrm{~cm}$ de largura por $22 \mathrm{~cm}$ a 23,3 cm de altura. Foram impressas em papel cartão com impressão colorida em uma das faces.

Outro fator reduziu o número de capas estudadas: a sua disponibilidade. Aquelas impressas nos anos 1939, 1940, 1951 e 1952 só foram encontradas fotocopiadas em preto e branco. Excetuando-se essas últimas, as outras estão organizadas cronologicamente a seguir.

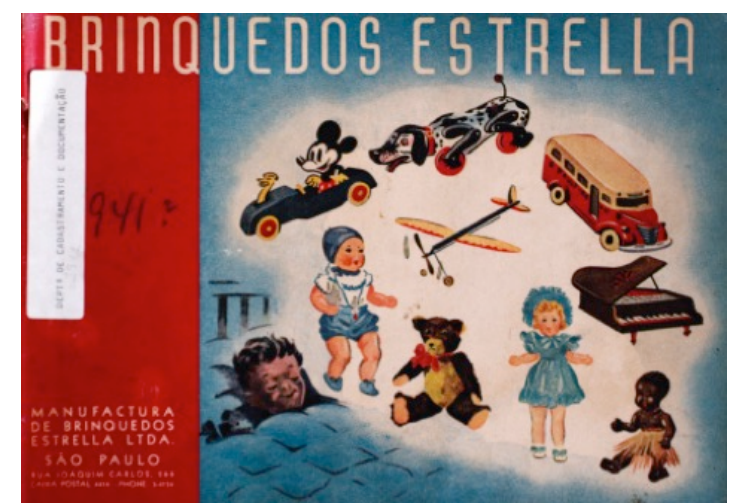

Figura 7

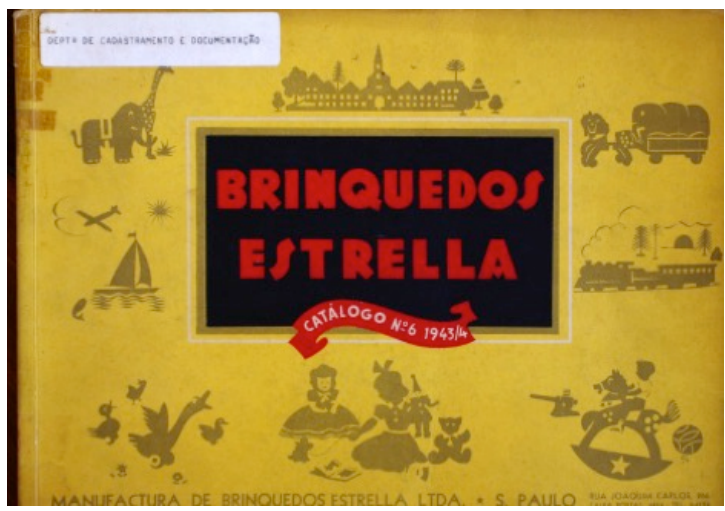

Figura 9

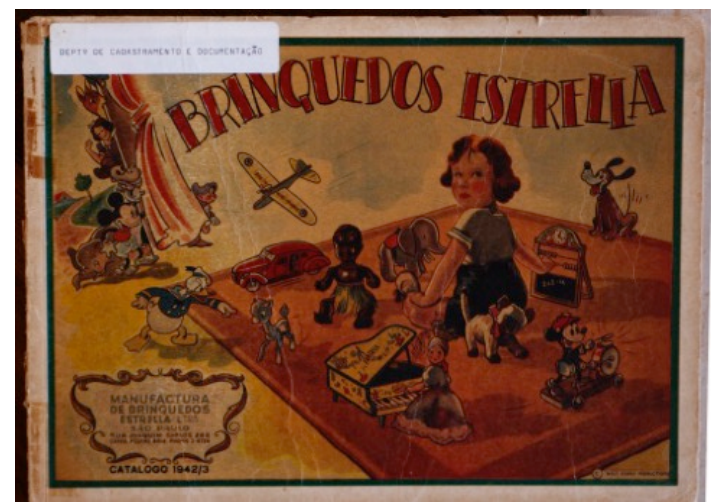

Figura 8

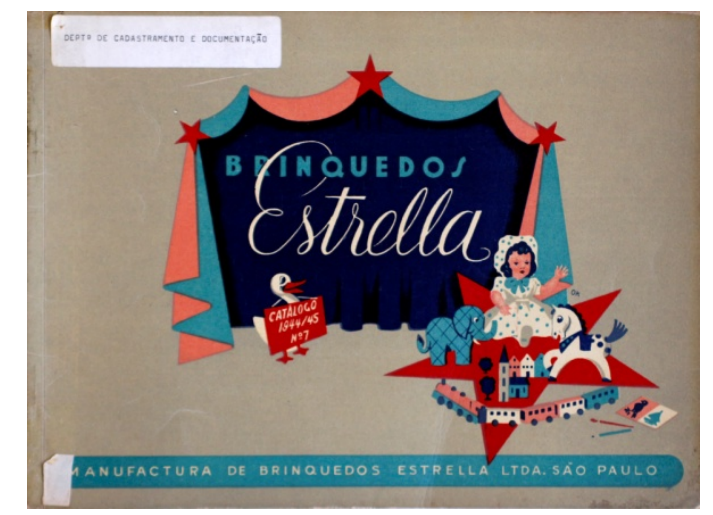

Figura 10

Na figura 7, a capa, de 1941, foi dividida verticalmente, a quarta parte à esquerda foi reservada para o nome da indústria e endereço sobre fundo vermelho, o restante para a ilustração que mostra um menino sonhando com os brinquedos Estrela, que parecem estar em movimento no ar. A repetição de cores compõe uma figura harmônica e o título na parte superior ocupa toda a extensão da área contribuindo para um sentido de coesão das duas partes.

A figura 8, capa feita em 1942, mostra uma menina, sentada no chão sob um tapete, com brinquedos ao redor que tem seu olhar direcionado ao título "Brinquedos 
Estrela" e que recebe a visita dos personagens Disney. A cortina em segundo plano e o título na margem superior sugerem movimento. Os dados da empresa aparecem no canto esquerdo inferior fazendo parte da ilustração.

A figura 9, de 1943, é marcada pelo contraste de cores que valoriza o título em letras vermelhas sobre um retângulo preto colocado sobre o fundo amarelo da capa. Os brinquedos aparecem sob forma de carimbos estilizados a uma só cor ao redor do título.

Na figura 10, a capa do catálogo $n$ ㅇ 7, de 1944, mostra, sobre um fundo cinza em um primeiro plano, brinquedos apoiados sobre uma estrela vermelha e em um segundo plano uma cortina emoldurada por tecido bicolor e pequenas estrelas vermelhas.

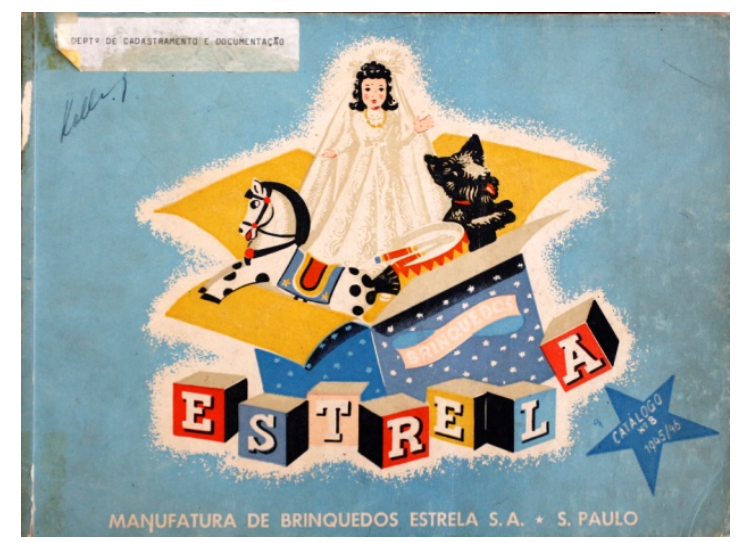

Figura 11

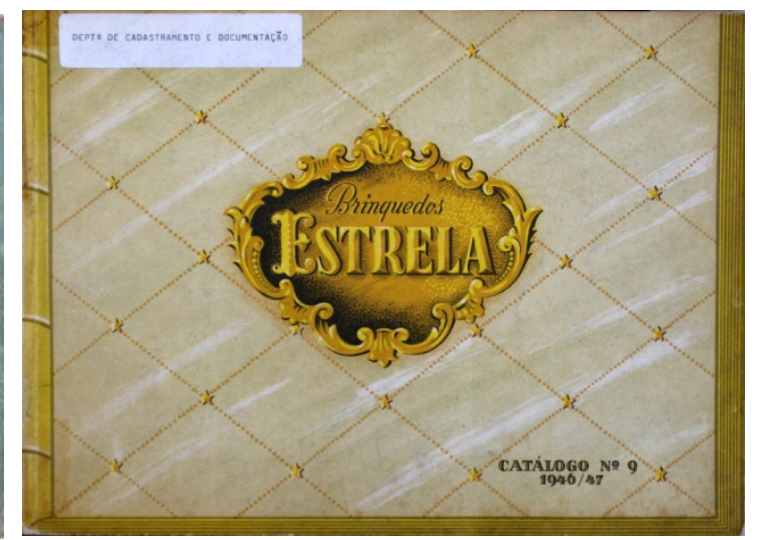

Figura 12

$\mathrm{Na}$ imagem em sequência (figura 11), há sobre o fundo azul claro a imagem de uma caixa decorada com pequenas estrelas onde se lê a palavra "brinquedos". Ela está aberta e dela saem brinquedos, abaixo, há cubos coloridos com as letras que formam a palavra "estrela".

A figura 12, diferente das anteriores, não mostra brinquedos, mas sim, um brasão dourado centralizado com o título sobre um fundo composto por linhas e pequenas estrelas douradas. Uma moldura dourada transcorre pelas margens laterais e inferior. A partir dessa edição não aparece mais na capa o nome completo da indústria, nem seu endereço. Somente o ano da edição e número do catálogo.

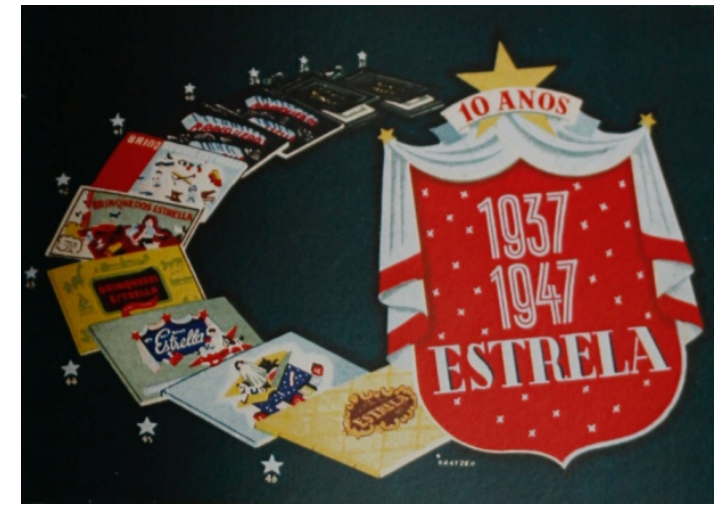

Figura 13

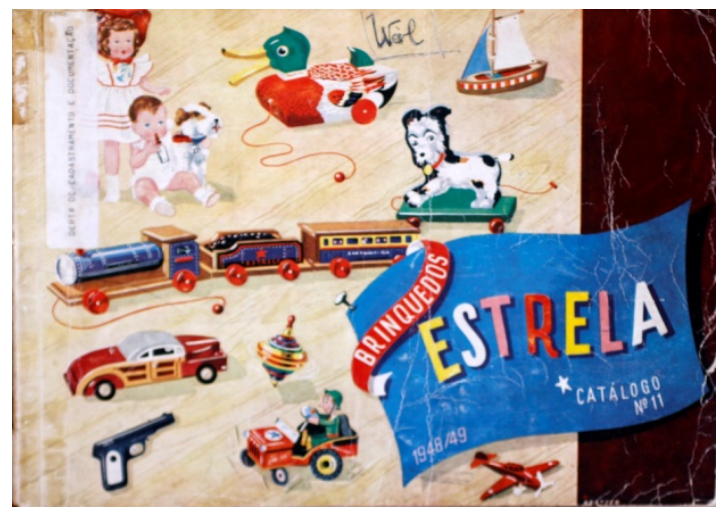

Figura 14 


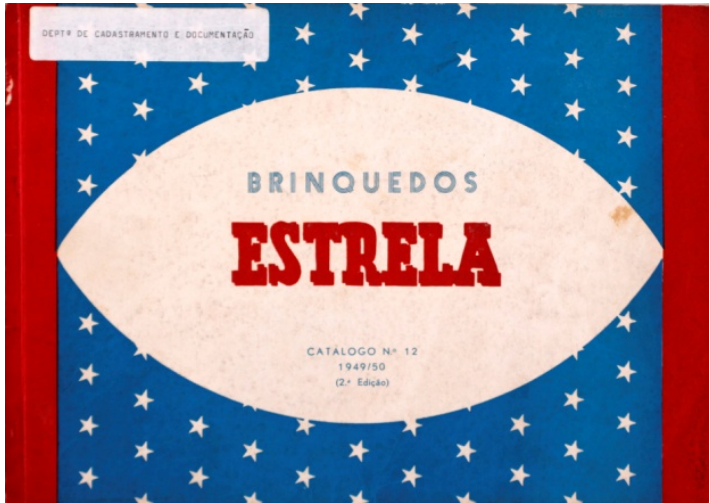

Figura 15

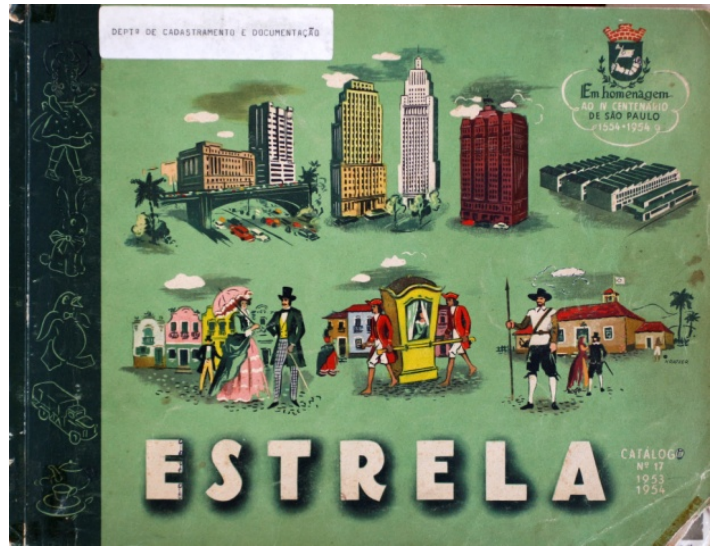

Figura 17

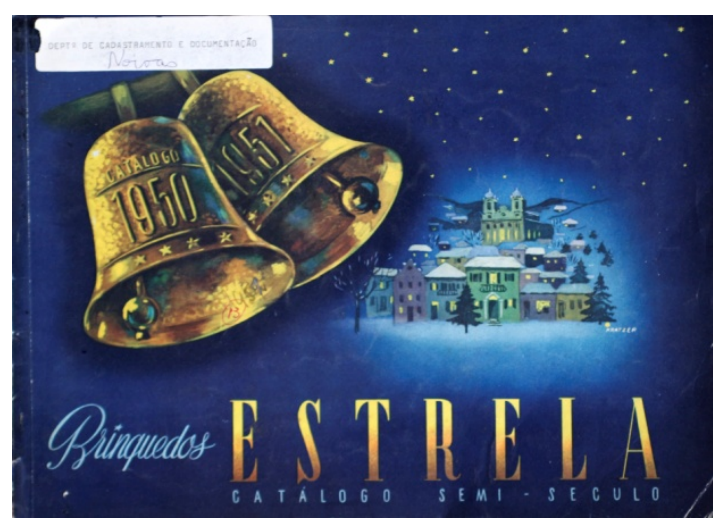

Figura 16

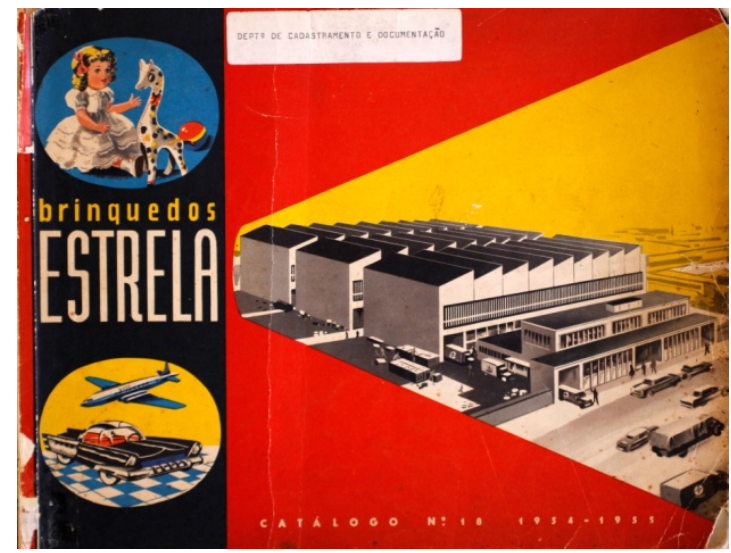

Figura 18

A figura 13 é a capa comemorativa pelos dez anos da empresa, a ilustração sugere um movimento de trás para frente, onde no início está o catálogo no 1 até o nono. Há um brasão vermelho ladeado por cortinas bicolores e estrelas douradas onde se lê o título e os dizeres 10 anos, com os números 1937-1947.

A imagem seguinte (Figura 14), do ano de 1948, novamente é uma imagem dividida verticalmente, onde o um quarto, à margem direita, imita uma textura orgânica em tom escuro. Na outra parte, sobre fundo trabalhado estão variados brinquedos compostos com uma bandeira em movimento onde se vê o título, numeração e anos de validade.

A figura 15 chama atenção para o contraste das cores branco, azul e vermelho. O título centralizado sobre uma forma geométrica branca ganha relevância. O fundo, azul com pequenas estrelas brancas contrasta com as molduras vermelhas das laterais.

$\mathrm{Na}$ figura 16, os elementos compõem uma cena natalina, com sinos em escala aumentada na parte superior esquerda, no plano ao fundo aparece a imagem de uma cidade sob neve. O fundo azul profundo tem estrelas que parecem cair do céu. Nessa capa os numerais que identificam os anos de validade, 1950-1951 - metade do século, do catálogo aparecem em evidência nos sinos dourados. "Brinquedos Estrela" está na parte inferior.

A capa seguinte (Figura 17), dividida verticalmente, tem no barrado à esquerda um fundo escuro onde aparecem brinquedos delineados. A ilustração na parte restante é uma homenagem ao quarto centenário de São Paulo. São retratados o viaduto do Chá, o vale do Anhangabaú, o edifício Altino Arantes, o edifício Martinelli e 
a fábrica da Estrela. Aparecem também cenas da origem da cidade: um bandeirante, dois homens de libré e um casal em frente a uma fileira de casas.

Na capa impressa em 1954 (Figura 18) há uma divisão vertical e outra em ângulo. Um quarto da área à esquerda é ocupada por uma faixa preta onde duas formas elípticas contém desenhos de brinquedos, na parte superior para meninas e na inferior para meninos. Entre as duas foi colocado o título em cores contrastantes. $\mathrm{Na}$ área restante, sobre o fundo vermelho, aparece um triângulo amarelo onde está inserido o desenho em perspectiva da unidade fabril da Estrela.

\section{CONCLUSÃO}

Dentro do âmbito da pesquisa da trajetória da marca Estrela nos anos 1940 e 1950, é certo que a marca Estrela (Figura 7), em qualquer uma de suas versões, não aparece nas capas de catálogo analisadas. Deve-se considerar, no entanto, que em oito das doze edições vistas, a forma geométrica poligonal de 10 lados que chamamos estrela aparece mesmo que em escala, cores e posições variadas.

Analisando os elementos técnico-formais vê-se que cada um das capas tem arranjos formais com unidade, muitas com movimento, são organizadas hierarquicamente ora dando valor ao título, ora à ilustração.

Quanto aos elementos estético-formais, o título "Brinquedos Estrela" aparece de formas diferentes em cada edição, ora na margem superior, ora na inferior, em movimento, ou não. Na capa de 1953, por exemplo a palavra "brinquedos" é subtraída.

As ilustrações também têm linguagem e tema variados. O contraste das cores é usado como elemento predominante outras vezes a cor é um elemento complementar.

Ou seja, podemos considerar que o conjunto de capas analisado não apresenta entre seus elementos composições semelhantes que poderiam ser classificadas dentro de um mesmo padrão gráfico.

Em cada capa, entre aquelas publicadas até 1954, é perceptível a mão e o projeto do artista, com autenticidade gráfica. Não há, nas artes das capas, uma preocupação por parte da indústria em garantir uma padronização gráfica ou colocar de forma veemente a marca da indústria. Eram vistas como uma ilustração, um trabalho do artista.

\section{REFERÊNCIAS}

ARRABAL, Rafael. Vozes da Estrela: quem não teve um brinquedo Estrela?. São Paulo: Tempo e Memória, s/d.

ADLER, Mario Arthur. Entrevista do ex-proprietário da Manufatura de Brinquedos Estrela. Concedida aos autores em 31 de agosto de 2015.

FAYAD, Claudia Maria Andino. Embalagens de brinquedos no Brasil: 1940-1980. 2010. 260f. Monografia (Pós-graduação). Fundação Armando Álvares Penteado, Curso de pós-graduação Embalagem 360ㅇ.

GORDINHO, Margarida Cintra et. al. Gráfica: arte e indústria no Brasil: 180 anos de história. São Paulo: Bandeirantes Gráfica e Editora, 1991. 
MANUFAURA de Brinquedos Estrela. Disponível na internet por http em:

$<$ http://estrela.com.br>. Acesso em 5 jan. 2016.

MEFANO, Ligia. O design de brinquedos no Brasil: Uma arqueologia do projeto e suas origens. 2005. 157f. Dissertação (Mestrado). Pontifícia Universidade Católica do Rio de Janeiro, Curso de pós-graduação em design.

MELO, Chico Homem de et. al. Linha do tempo do design gráfico no Brasil. São Paulo: Cosac Naify, 2011.

MUSEU Histórico Nacional. Disponível na internet por http em:

<http://www.museuhistoriconacional.com.br/mh-g-19.htm>. Acesso em 5 jan. 2016.

O ESTADO de S. Paulo. p.1, 9 de julho de 1954.

O ESTADO de S. Paulo. p.51, 22 de março de 1987.

O ESTADO de S. Paulo. p.b11, 10 de outubro de 2015.

VILLAS-BOAS, André. Sobre análise gráfica, ou algumas estratégias didáticas para a difusão de um design crítico. In: Arcos Design, Rio de janeiro, v.5, p. 2-17, dez 2009. Disponível na internet por http em: <http://www.esdi.uerj.br/arcos/arcos-04-2/042.arcos-design-04-2-completo.pdf>. 